\title{
Probiotics as Living Drugs to Resolve Urinary Tract Infections
}

\author{
Aziz Fatima* \\ Department of Microbiology, Jinnah University for Women, Karachi, Pakistan
}

\begin{abstract}
The increasing consumption of probiotics is due to progress made in understanding the use of probiotics. In the past, probiotics were used to treat UTIs mostly because of an alarming concern regarding rise in antibiotic resistance.

Lactobacillus and Bifidobacterium are mostly use on a large scale nowadays. They are gut beneficial bacteria. These organisms have enzymes, $\mathrm{H}_{2} \mathrm{O}_{2}$, lactic acid, and other acids which are utilized as antimicrobial agents to treat digestive pain, eczema, tumors, and ulceration. Dairy-based products like milk, yogurt, cheese, ice cream, milk powder, dark chocolate, fermented milk etc., mostly contain probiotics.

Samples were collected from different markets. All these samples were enriched for 24 hours following morphology observation by catalase test, gram staining and biochemical test. Antimicrobial activity was checked by measuring zone of inhibition formed by isolated species against uropathogens, namely E-coli and Klebsiella. A current study showed results that were probable to promote rate of UTI treatment in women who are above 50 years. It was found that natural products contain probiotics which allow the consumer to get their beneficial health effect. These probiotics colonize in the intestine and act as a barrier to prevent urinary tract infections.
\end{abstract}

Keywords: Probiotics, Urinary Tract Infections, Lactobacillus, Bifidobacterium, E.coli, Colorectal cancer.

\section{INTRODUCTION}

There are 2 types of bacteria i.e. good bacteria and the bad ones. Good microorganisms which provide benefits to the human body are most probably called probiotics. Probiotics helps to improve microbial balance in host body. These are very useful as well as human friendly bacteria and are used as microbial treatment [1].

Microbial species with probiotic properties belongs to Bifidobacterium and genera Lactococcus.

Antimicrobial techniques were seen in Lactobacillus which include adhesion inhibitors, organic acids, carbon dioxide, bacteriocins, hydrogen peroxide, and low-molecular weight antimicrobial substances [2]. Antimicrobial activities of these Lactobacillus species is mainly relatable with production of organic acids and alternation of $\mathrm{Ph}$ [3].

(Madden, J. A. J., \& Hunter) investigations have showed that probiotics could stop the threat of eczema in children. Some studies have been conducted on animals which prove that probiotics have anti-tumor property as well as antioxidant property to fight infections. Probiotics have noteworthy functions to reduce digestive pain, helps in sensitive bowel, ulcerative colitis and is useful to avoid allergies [4].

Probiotics have a list of mechanism of action ranging from immunomodulation, short chain fatty acid, bacteriocin production, lowering of gut $\mathrm{pH}$ and nutrient competition to stimulate barrier function of mucosa. Probiotics could influence several phases of innate and acquired responses which include: induction of IgA secretion, phagocytosis,

*Address correspondence to this author at the Department of Microbiology Jinnah University for Women Karachi, Pakistan

Email: azizfatima1988@gmail.com
T-cell responses modification, improvement in responses of $\mathrm{Th} 1$ and weakening responses of Th2.

The main products are diary-based including fermented milks, cheese, ice cream, , dark chocolates, buttermilk, yogurts, milk powder and curd [5], whereas nondairy food products consist of nutrition bars, variety of juice, cereals and soy based products [6].

\section{URINARY TRACT INFECTION}

UTIs commonly begin as infections of bladder (cystitis), but can progress into pyelonephritis i.e. acute kidney infections, and finally causing renal failure and scarring. These infections can be treated by probiotics i.e. non antimicrobial therapeutic approaches, which prevent bacteria from colonizing and inhibiting adherence of bacteria. Tsai CC, et al. [2] show that prevention from pathogenic infections caused by $E$-coli, Salmonella and Helicobacter pylori can be achieved from the use probiotics [7].

Barrons $\mathrm{R}$ and Tassone $\mathrm{D}$, have suggested fighting against UTIs by consuming probiotics and fermented milk products [8]. Lactobacilli species can act against UTIs as they have several growth effecters including hydrogen peroxide, bacteriocin, biosurfactants and lactic acid [9]. These species can adversely affect fimbrial structure and adhesion that seem to be inhibitory for growth of uropathogenic E.coli [10].

\section{PREVENTION OF VAGINITIS}

Colonization of pathogenic bacteria including Gardnerella vaginalis or Escherichia coli is generally accounted as abnormal flora. In women, this abnormal floracan cause symptomatic infections in the vagina [11]. Bacterial vaginitis 
can be easily cured by orally administering Lactobacillus rhamnosus GR-1 and Lactobacillus reuterias mentioned in previous study [12].

\section{CONSTIPATION TREATMENT}

Different studies shows that using probiotic strain $L$. rhamnosus, L. shirota and B. infantis, decrease in abdominal pain and increase in defecation frequency have seen in people with irritable bowel syndrome (IBS) and constipation [13,14].

\section{COLORECTAL CANCER}

Western diet is a diet that consists of low fiber or increase consumption of fat and meat. This diet is the main cause of colorectal cancer. It has been observed that this cancer can increase the levels of Clostridium and Bacteroides and can decrease Bifidobacterium levels [15]. Reduction in the colorectal cancer actual risk and fecal enzyme activity can be achieved by selective intake of lactobacilli [16].

\section{LACTOSE INTOLERANCE}

Probiotics can effectively act as immune system enhancer [17]. Milk sugar (lactose) is converted into lactic acid by LAB i.e. lactic acid bacteria that make conditions acidic and inhibit pathogenic growth.

\section{STUDY AIM}

To isolate the probiotics from natural products and determine high efficacy of probiotics against uropathogens.

\section{MATERIALS AND METHODOLOGY}

For the isolation of probiotics, natural products (yoghurt, butter, infant's powder milk, chocolate and cheese etc.) were used from different markets samples was collected. Samples include butter, different infant's powder milk, chocolate, yoghurt, apple, cheese, apple peels etc.

Different samples were used for the isolation of multiple species of probiotics. 1 gram of sample were added in $5 \mathrm{ml}$ MRS broth to enriched the samples for growth enhancement and incubated for 18 to 24 hours at $37^{\circ} \mathrm{C}$.

Next day used De Man Rogosa and Sharpe (MRS) agar, streaking were done on plates and incubated for 24 hours at $37^{\circ} \mathrm{C}$ for the growth of probiotics. Next day after 24 hours colonies were showed on MRS agar and microscopy were done by gram staining. After that some catalase test and sugar tests were applied like lactose, mannitol, sucrose, glucose for the confirmation of microbial specie of probiotics, and then antimicrobial activity of probiotics was checked.

\section{ANTIMICROBIAL ACTIVITY}

In this research used molten nutrient agar that was poured into sterilized Petri plates. After agar solidified used spread plate technique on the agar surface to spread the samples of probiotics on agar surface, then well were made on MRS agar which contain samples of probiotics, $0.1 \mathrm{ml}$ inoculum were added from MRS broth, that have tested organisms such as (Klebsiella specie and E.coli). Next day zones were measured in $\mathrm{mm}$ from incubated plates.

\section{RESULTS}

Using different samples from natural products, we isolated several species of probiotics. Moreover, most of them showed positive zone of inhibition (Table $\mathbf{1}$ ).

Table 1. Sugars Utilization Test.

\begin{tabular}{|l|c|c|c|c|}
\hline $\begin{array}{l}\text { Sugar } \\
\text { Name }\end{array}$ & $\begin{array}{c}\text { Enterococcus } \\
\text { durans }\end{array}$ & $\begin{array}{c}\text { Streptococcus } \\
\text { thermophillus }\end{array}$ & $\begin{array}{c}\text { Lactobacillus } \\
\text { bulgaricus }\end{array}$ & $\begin{array}{c}\text { Lactobacillus } \\
\text { reuteri }\end{array}$ \\
\hline Glucose & $+\mathrm{VE}$ & $+\mathrm{VE}$ & $+\mathrm{VE}$ & $+\mathrm{VE}$ \\
\hline Mannitol & $-\mathrm{VE}$ & $-\mathrm{VE}$ & $-\mathrm{VE}$ & $-\mathrm{VE}$ \\
\hline Sucrose & $-\mathrm{VE}$ & $-\mathrm{VE}$ & $-\mathrm{VE}$ & $-\mathrm{VE}$ \\
\hline Lactose & $+\mathrm{VE}$ & $+\mathrm{VE}$ & $+\mathrm{VE}$ & $+\mathrm{VE}$ \\
\hline
\end{tabular}

Table 2. Zones of Inhibbition against Klebsiella Species and E.Coli.

\begin{tabular}{|l|c|c|c|}
\hline Samples & Tested organism & Isolated organism & Antimicrobial activity \\
\hline Chocolate & Klebsiella specie & Enterococcus durans & \\
\hline Chocolate & E.coli & Enterococcus durans & \\
\hline
\end{tabular}


Table 2 contd.

\begin{tabular}{|c|c|c|c|}
\hline Samples & Tested organism & Isolated organism & Antimicrobial activity \\
\hline Butter & Klebsiella specie & Enterococcus durans & \\
\hline Butter & E.coli & Enterococcus durans & \\
\hline Infant's milk powder & Klebsiella specie & Lactobacillus reuteri & \\
\hline Infant's milk powder & E.coli & Lactobacillus reuteri & \\
\hline Infant's milk powder (lactogen) & Klebsiella specie & Lactobacillus reuteri & \\
\hline Infant's milk powder (lactogen) & E.coli & Lactobacillus reuteri & \\
\hline Yoghurt & Klebsiella specie & Lactobacillus bulgaricus & \\
\hline
\end{tabular}


Table 2 contd.

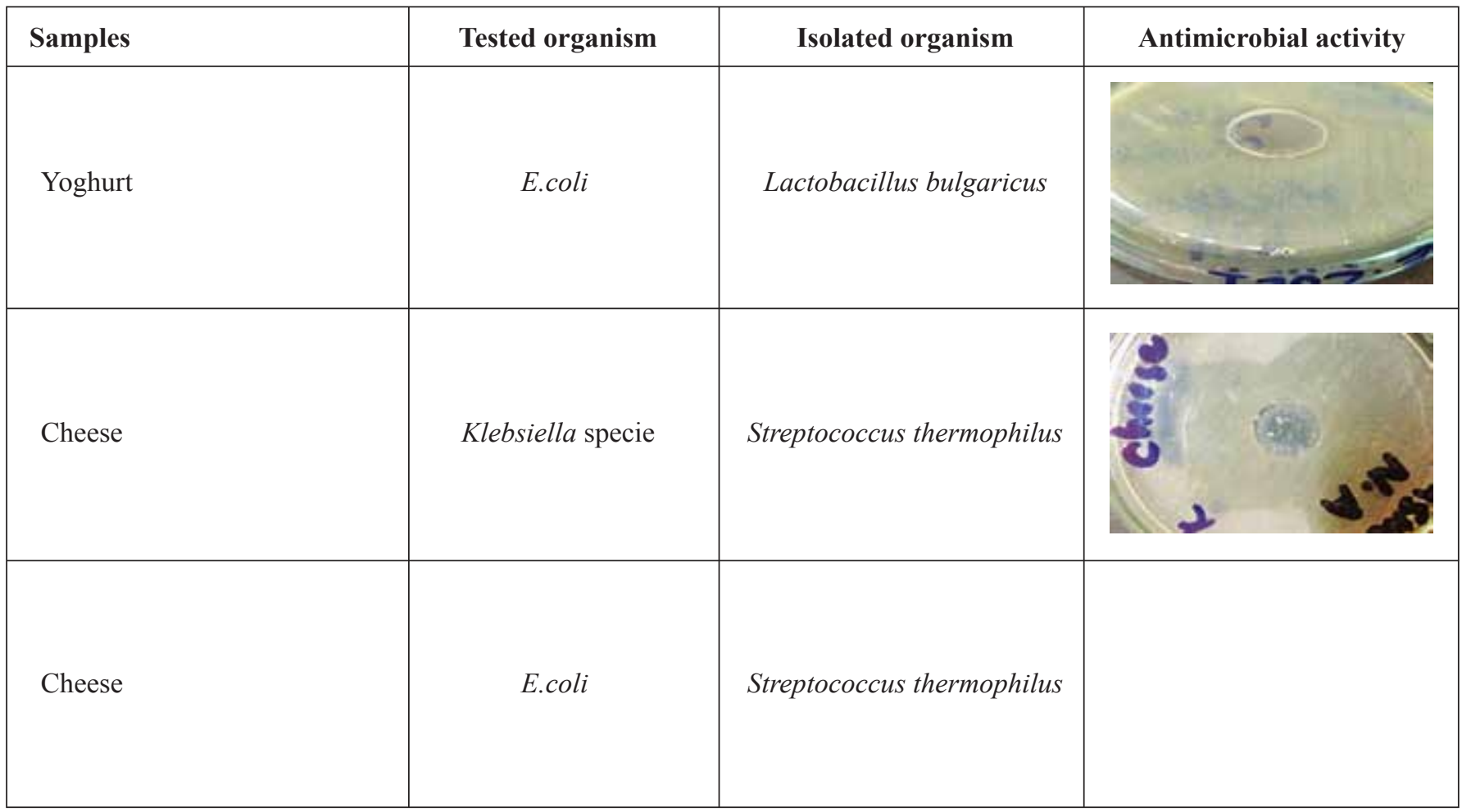

\section{ANTIMICROBIAL ACTIVITY}

Agar well diffusion technique was performed to check probiotic antimicrobial activity against E. coli and klebsiella i.e. uropathogenic organisms. Sensitive zone was observed which is an indication of probiotic showed antimicrobial activity against pathogenic bacteria (Table 2 ).

\section{DISCUSSION}

In the current study, different probiotic species were isolated from collected samples which include: chocolates, butter, dairy product, different infant's milk powder etc. Gram staining tests were performed on the isolated species which resulted in identification of Coccobacilli and Gram positive bacilli. Several biochemical tests were also performed for the confirmation of genus and species. From infant's milk powders, Lactobacillus reuteri was isolated. It was found to be gram positive and with thick rods (Fig. 1). Bacterial vaginitis can be easily cured by orally administering Lactobacillus rhamnosus GR-1 and Lactobacillus reuteri [18].

From the cheese samples, Streptococcus thermophiles was isolated. Through catalase test which was negative, it was confirmed that isolate species were of Streptococcus thermophilus. Its morphology was found to be cocci in bunches diplococcic and tetrads (Fig. 2). Streptococcus thermophiles plays a vital role in food industry and are mostly required in the making of dairy products

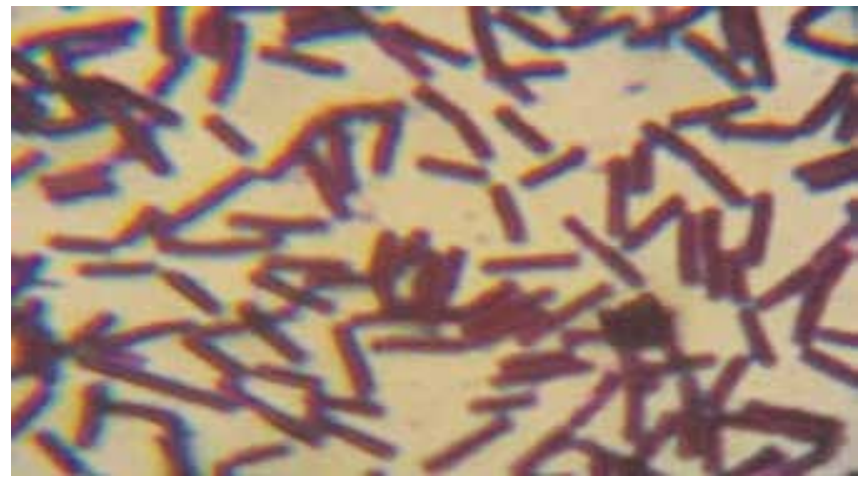

Fig. (1). From Infant's Powder Milk, Isolated Lactobacillus reuteri.

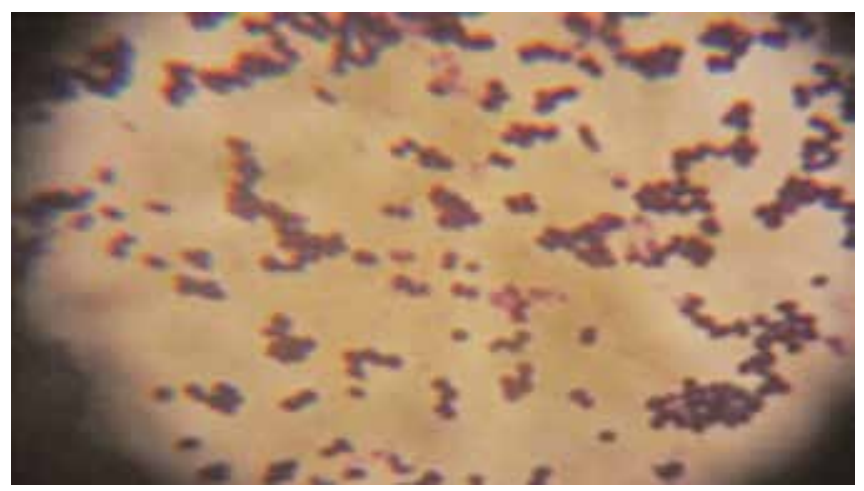

Fig. (2). From Samples of Cheese, Isolated Streptococcus thermophiles. 
From yoghurt samples, Lactobacillus bulgaricus was isolated. It was found to be Gram positive bacteria with positive catalase test. Its morphology consisted of highly long rods (Fig. 3).

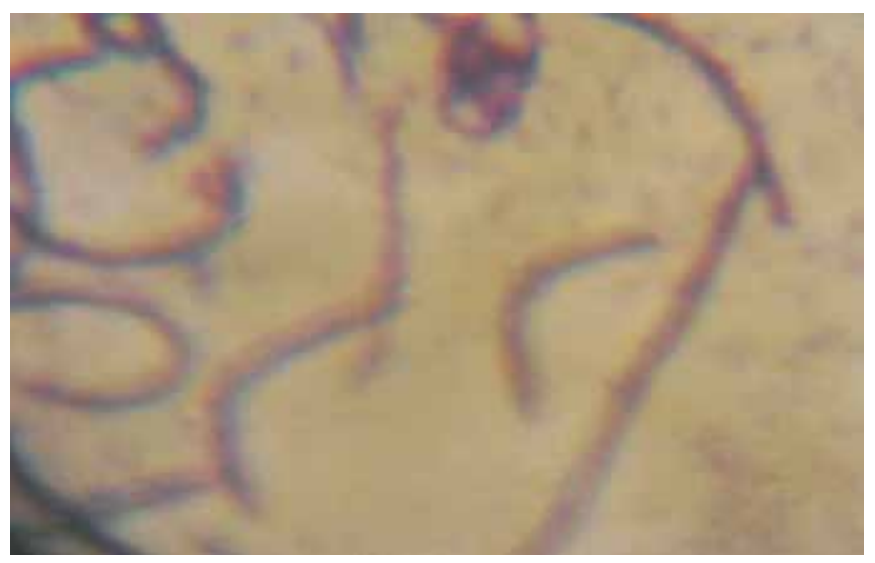

Fig. (3). From Samples of Yoghurt, Isolated Lactobacillus bulgaricus.

From few chocolate and butter samples, Enterococcus durans was isolated. It showed negative result in catalase test and positive results for glucose and lactose sugar. It was found to be gram positive bacteria. Its morphology consists of ovoid shape, short chains and grouped in pairs (Fig. 4).

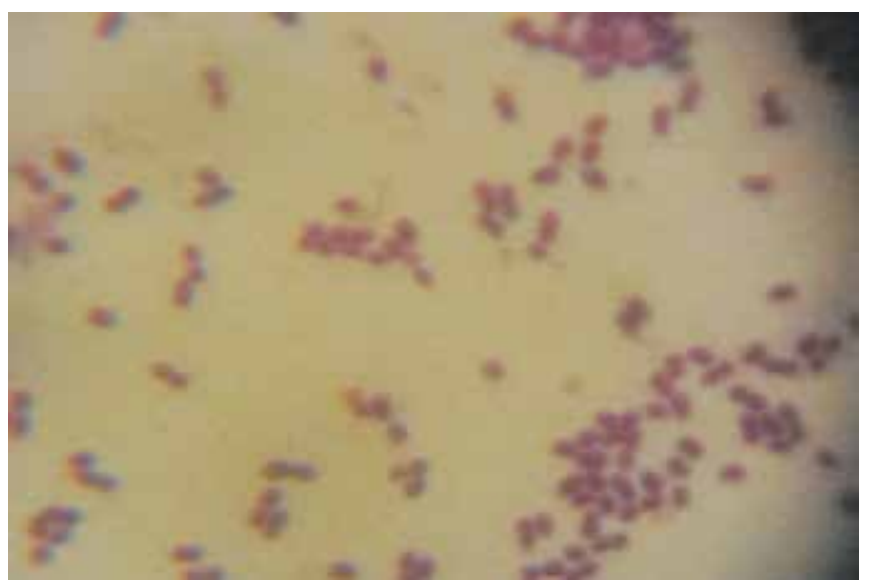

Fig. (4). From Samples of Butter and Chocolate, Isolated Enterococcus durans.

To check the antimicrobial activity of the species isolated from samples, agar well diffusion technique was performed. Klebsiella species and E.coli were the uropathogens against which zone of inhibition was measured. Against E.coli, antimicrobial activity was observed by the cultures of Lactobacillus reuteri, Enterococcus durans, Streptococcus thermophilus and Lactobacillus bulgaricus (Fig. 5). The measured zone of inhibition on the agar plate of these cultures was found to be $30 \mathrm{mM}, 24 \mathrm{mM}, 21 \mathrm{mM}$ and $21 \mathrm{mM}$ respectively (Table 3).

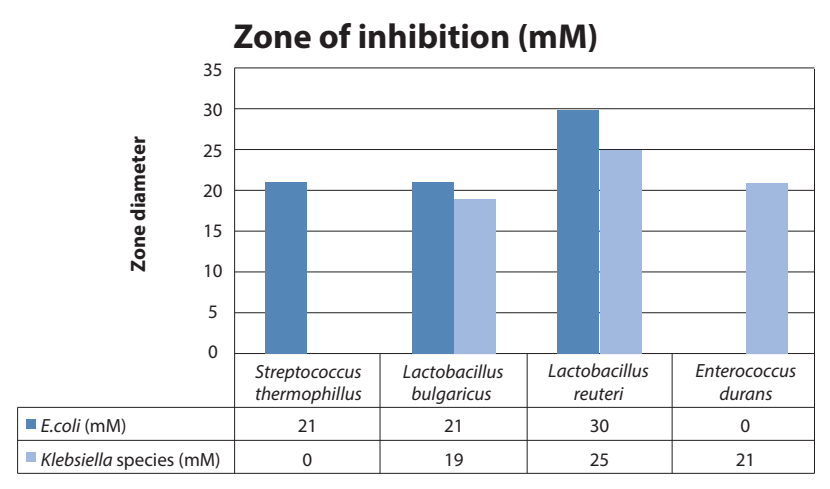

Fig. (5). Measurements of Zones of Inhibition against Enteric Bacteria in Graph.

Table 3. Measured Zone of Inhibition of Isolated Probiotics Species against Enteric Bacteria.

\begin{tabular}{|l|l|l|c|}
\hline S. no. & Test organisms & Name of isolates & $\begin{array}{c}\text { Zone of inhibition } \\
(\mathbf{m M})\end{array}$ \\
\hline \multirow{2}{*}{1} & \multirow{2}{*}{ E.coli } & Lactobacillus reuteri & $30 \mathrm{mM}$ \\
\cline { 3 - 4 } & & Enterococcus durans & $24 \mathrm{mM}$ \\
\cline { 3 - 4 } & & Lactobacillus bulgaricus & $21 \mathrm{mM}$ \\
\cline { 3 - 4 } & & Streptococcus thermophilus & $21 \mathrm{mM}$ \\
\hline 2 & \multirow{2}{*}{ Klebsiella species } & Lactobacillus reuteri & $25 \mathrm{mM}$ \\
\cline { 3 - 4 } & & Enterococcus durans & $21 \mathrm{mM}$ \\
\cline { 3 - 4 } & & Lactobacillus bulgaricus & $19 \mathrm{mM}$ \\
\cline { 3 - 4 } & & Streptococcus thermophilus & $0 \mathrm{mM}$ \\
\hline
\end{tabular}

Against klebsiella species, antimicrobial activity was observed by the cultures of Lactobacillus reuteri, Enterococcus durans, Lactobacillus bulgaricus, and Streptococcus thermophilus. The measured zone of inhibition on the agar plate of these cultures was found to be $25 \mathrm{mM}, 21 \mathrm{mM}, 19 \mathrm{mM}$ and $0 \mathrm{mM}$ respectively (Table $\mathbf{3}$ ).

Through this study, beneficial health effects of dairy and natural food products can be seen in the protection of urinary tract infections. Menopausal women are at most risk for developing UTIs and are commonly seen in this age group; hence they can attain more benefit from natural and dairy products as they help in recovery from UTIs and provide protection against pathogens causing urinary tract infections. In an emergency we can use these natural products to start the treatment of infection at home.

\section{CONCLUSION}

In menopausal women, there is an increased risk of UTIs, due to several factors. Low vaginal $\mathrm{pH}$ causes UTIs by promoting survival of different pathogenic bacteria. In the current study, it is concluded that we can use home product like chocolates, infant's milk powder, cheese etc. to start the treatment of urinary tract infection at home and immediately which is also helpful to halt the increase infection. We isolated different species of probiotics which showed positive antimicrobial 
activity. This conclusion promotes the use of probiotics in the women who are 50 years and above for beneficial health effects. These probiotics, like lactic acid bacteria, can be found in natural products and provide protective effect by colonizing in the gut system and act as a barrier against uropathogens. They can also be used to treat UTIs.

\section{CONFLICT OF INTEREST}

Declared none.

\section{ACKNOWLEDGEMENTS}

Declared none.

\section{REFERENCES}

[1] Gibson GR, Roberfroid MB. Dietary modulation of the human colonic microbiota: Introducing the concept of prebiotics. J Nutr 1995; 125(6): 1401-12.

[2] Holzapfel WH, Haberer P, Geisen R, Björkroth J, Schillinger U. Taxonomy and important features of probiotic microorganisms in food and nutrition. Am J Clin Nutr 2001; 73(2): 365S-73S.

[3] Goudarzi L, Kermanshahi RK, Moosavi-Nejad Z, Dalla MM. Evaluation of antimicrobial activity of probiotic lactobacillus strains against growth and urease activity of proteus spp. J Med Bacteriol 2017; 6(3,4): 31-43.

[4] Ołdak A, Zielińska D, Rzepkowska A, Kołożyn-Krajewska D. Comparison of antibacterial activity of Lactobacillus plantarum strains isolated from two different kinds of regional cheeses from Poland: Oscypek and Korycinski Cheese. BioMed Res Int 2017; 2017.

[5] Stanton C, Gardiner G, Meehan H, et al. Market potential for probiotics. Am J Clin Nutr 2001; 73(2): 476S-83S.

[6] Ewe JA, Wan Nadiah WA, Liong MT. Viability and growth characteristics of Lactobacillus in soymilk supplemented with B-vitamins. Int J Food Sci Nutr 2010; 61(1): 87-107. DOI: $10.3109 / 09637480903334163$

[7] Tsai CC, Lin PP, Hsieh YM. Three Lactobacillus strains from healthy infant stool inhibit enter toxigenic Escherichia coli grown in vitro. Anaerobe 2008; 14: 61-7. DOI: 10.1016/j.anaerobe.2007.11.003

[8] Barrons R, Tassone D. Use of Lactobacillus probiotics for bacterial genitourinary infections in women: A review. Clin Ther 2008; 30: 453-68. DOI: 10.1016/j.clinthera.2008.03.013
[9] Borges S, Silva J, Teixeira P. The role of lactobacilli and probiotics in maintaining vaginal health. Arch Gynecol Obstet 2014; 289(3): 479-89.

DOI: $10.1007 / \mathrm{s} 00404-013-3064-9$

[10] JuárezTomás MS, Saralegui Duhart CI, De Gregorio PR,Vera Pingitore E, Nader-Macías ME. Urogenital pathogen inhibition and compatibility between vaginal Lactobacillus strains to be considered as probiotic candidates. Eur J Obstet Gynecol Reprod Biol 2011; 159: 399-406. DOI: 10.1016/j.ejogrb.2011.07.010

[11] Wasiela M, Hanke W, Kalinka J. Association between abnormal microbiological flora of the lower genital tract in early pregnancy and socioeconomic, demographic and environmental risk factors. Med Sci Monit 2001; 7: 1250-5.

[12] Bu LN, Chang MH, Ni YH, Chen HL, Cheng CC. Lactobacillus casei hamnosus Lcr35 in children with chronic constipation. Pediatr Int 2007; 49: 485-90.

DOI: 10.1111/j.1442-200X.2007.02397.x

[13] Koebnick C, Wagner I, Leitzmann P, Stern U, Zunft HJ. Probiotic beverage containing Lactobacillus casei Shirota improves gastrointestinal symptoms in patients with chronic constipation. Can J Gastroenterol 2003; 17: 655-9. DOI: $10.1155 / 2003 / 654907$

[14] Benno Y, Mitsuoka T, Kanazawa K. Human faecal flora in health and colon cancer. Acta Chirurgica Scand 1991; 521: 15-23.

[15] Hirayama K, Rafter J. The role of probiotic bacteria in cancer prevention. Microbes Infect 2000; 2(6): 681-6. DOI: $10.1016 /$ S1286-4579(00)00357-9

[16] Kumura H, Tanoue Y, Tsukahara M, Tanaka T, Shimazaki K. Screening of dairy yeast strains for probiotic applications. App J Dairy Sci 2004; 87(12): 4050-6. DOI: $10.3168 /$ jds.S0022-0302(04)73546-8

[17] Anukam K, Osazuwa E, Ahonkhai I, et al. Augmentation of antimicrobial metronidazole therapy of bacterial vaginosis with oral probiotic Lactobacillus rhamnosus GR-1 and Lactobacillus reuteri RC-14: Randomized, double-blind, placebo controlled trial. Microbes Infect 2006; 8: 1450-4. DOI: 10.1016/j.micinf.2006.01.003

[18] Felis GE, Dellaglio F. Taxonomy of lactobacilli and bifidobacteria. Curr Issues Intest Microbiol 2007; 8: 44-61. 